\title{
PSYCHOLINGUISTIC ANALYSIS OF THE PSYCHOANA- LYTICAL PROCESS (BASED ON THE MATERIAL OF A PATIENT'S NARRATIONS OF THEIR DREAMS)
}

\begin{abstract}
Andrey V. Rossokhin
Lomonosov Moscow State University

Moscow

The work is aimed at the studying of the reflexive process of a personality during psychoanalysis, which has never been researched empirically basing on the material of a subject's narrations of their dreams. It was shown that during the psychoanalytical process the reflexive processes of a personality enhance, become more active and change qualitatively. As reflection develops, the subjects start to think reflexively about their dreams, which leads to qualitative and quantitative change of intrapsychic images. The extracommunicative direction of dreams during psychoanalysis is replaced by the intrapsychic one, and the content of the reflexive processes changes qualitatively. The amount of ascertaining statements decrease, more frequent is detailed description of inner feelings and emotions of the subject.
\end{abstract}

Keywords: personality, reflection, psychoanalysis, altered states of consciousness, psychoanalytical process, dreams, psycholinguistic analysis.

Basing on the understanding of reflection as the process of sensemaking and sense-genesis, in this study we research personal reflection as the mechanism of qualitative change of value and sense items and the integration of the personality into a new, more integrated state. Cultural and historical understanding (Asmolov, 1999) of the personality reflection as the capability of the personality to implement reflection of nonreflexive psychic content (Rossokhin, 2009), reconsidering not only the latter, but also their own reflexive strategies, the ways of inner reflection and understanding are the things we're interested in when examining the psychoanalytic process. Psychoanalysis presents unique empirical material for the research of the dynamics of personality reflection and its

Research sponsored by Russian Foundation for Humanities, project No. 09-06-00616a 
impact on different aspects of vital activity of the personality (Colombo \& Michels, 2007; Dahl, 1972; 1974; Ellman, 2005; Fonagy, 1999; 2002; Gullestad, 2007; Kernberg, 2006; Luborsky, Barber, \& Diguer, 1993; Wallerstein, 2009; Wyatt, 1986).

The present psycholinguistic research is focused on studying the versatile influence of the reflexive process of the personality on the intrapsychic dynamics of dreams (Lewin, 1955; Tolchin \& Carr, 2007). The research is based on the narrations of patients who took part in long-term psychoanalysis of their dreams.

The object of the research was the narrations of dreams.

The subject of the research was the intrapsychic dynamics of dreams.

The objective of the research is to study the intrapsychic dynamics of dreams during psychoanalytical process.

Hypotheses: During psychoanalysis the following processes take place: 1) activation and qualitative change of reflexive processes of a personality; 2) change of reflexive content of the memories of the dreams, namely the quantity of reflexive messages increases, and short abrupt statements are replaced by detailed analysis; 3 ) change of sense content of the objects of the interior reality of the subject - important object acquires new personality sense; 4) qualitative change of the dreams, namely: instead of extracommunicative they become intrapsychically oriented; 5) qualitative and quantitative change of intrapsychic images in the narrations of a subject about their dreams; 6) quality and volume of the subject's dreams increase.

The research empirical material is the narrations of dreams of three patients who had attended psychoanalysis during several years 4 times a week. Tape records were transcripted into text. All dreams mentioned were highlighted. The transcripts of Mrs. W, Mr. X. and Mrs. M. include respectively 122,148 and 200 dream narrations.

\section{Research No. 1. The dynamics of reflexive processes during psyochanalysis: extracommunicative and intrapsychical orientation (the case of Mrs. W.)}

From the text of each dream narration the context $(5$ words preceding and 5 words following) for the word "I" was extracted as the word around which the maximal quantity of reflection-related words and expressions will be concentrated. The next stage of text processing was the follow- 
ing. According to the abovementioned hypothesis, from the "I"-context words and expressions that were related to the following categories were extracted.

Reflection-important words - words and expressions showing that the subject is reflexively active.

Indefinite words - protective words and expressions, which make the subject's speech highly active, while their reflexive activity is absent. We can note the so called 'protective speech' of the subject.

Emotionally nuanced words - words and expressions containing any kind of emotional nuance.

Communicative words - words and expressions testifying the communicative intentions of the subject.

The next algorithm of the research was the following. For each dream, the quantity of words in each category was counted and the coefficient of the character frequency of this category was calculated (the quantity of words in the category divided by the whole quantity of words in the context).

The results were processed in the statistic package SPSS by means of one-factor dispersion analysis.

Results. Reflexively important words. According to the diagram of the character frequency of reflexive words, the quantity of reflexively important words during psychoanalytic process increases in general and in the second period as compared to the first one. Statistic data processing showed that the difference between the two years' indexes is statistically significant $(p<0.01)$.

Indefinite words. According to the diagram of the character frequency of indefinite words, their character frequency decreases gradually, and their general amount in the second year of the psychoanalytical process is significantly lower compared to the first year.

Statistic data processing showed that the difference between the two years' indexes is not statistically significant - significance coefficient equals 0.260 (>0.05). Within the framework of the present research we can say that some decrease tendencies take place.

Emotionally nuanced words. According to the diagram of emotionally nuanced words character frequency, their character frequency increases gradually and their general amount in the second year of the psychoanalytical process increases as compared to the first year. Statistic data processing showed that the difference between the two years' indexes is statistically significant $(p<0.01)$. 
Communicative words. According to the diagram of communicative words character frequency, their character frequency decreases gradually, and their general amount in the second year of the psychoanalytical process is significantly lower as compared to the first year.

Statistic data processing showed that the difference between the two years' indexes is statistically significant $(\mathrm{p}<0.01)$.

Comparative analysis of the results. As time passes, in Mrs. W.s narrations of her dreams the amount of reflexively significant words increases, and that of indefinite words becomes lower. It shows that the protective mechanisms (A. Freud, 1973) of the subject during psychoanalytical process gradually weaken, there is less "protective speech." Mrs. W. has more freedom speaking about her feelings, thoughts and emotions, and consequently starts doing more productive reflexiveanalytic work.

At the same time, the extracommunicative orientation of the dreams decreases significantly, the reflexive activity is oriented not outside, but at the inner processes of the personality, the subject talks more often about the feelings and emotions in the dreams.

\section{Research No. 2. Change of reflexive content of narration of dreams (case of Mr. X.)}

From the text of each dream narration reflexive sentences, expressions, phrases or words were extracted. Then they were classified by three forms which characterize qualitative reflexive content, which we named as can be seen below.

Statement - the subject only names any kind of his consition, feeling, reaction, etc. E.g. "I feel bad," "I'm angry as hell," "I feel joy."

Description - the subject describes his feelings more detailed than in the first case. For example: "It's tough for me, I feel as if I was a bag unlaced at the bottom," "I feel very aggressive," "I have a child's body, I'm a boy but act like an adult."

Analysis - the subject thinks, analyzes his feelings, sees causes and consequences, can explain why he feels or thinks exactly this way etc. E.g. "when I am such a double person I hate everyone," "I can't tell him anything because he'll kill me if I do."

Then average character frequency was calculated for each of the three reflection forms according to the three psychoanalysis years. The 
results were processed in the statistic package SPSS by means of onefactor dispersion analysis.

Results. Passing on to every following year, the qualitative content of the reflexive processes changes. There are less simple statements, detailed descriptions of the subject's interior feelings become more frequent. At the same time, the amount of analyzed information grows, the subject tends to think more, acquires the capability to ask himself questions and seek answers.

Statistic data processing showed that the difference between the indexes of the three analyzed years: 1$)$ for the 'statement' reflexive form is statistically significant $(p<0.01) ; 2)$ for the 'description' reflexive form isn't statistically significant - significance coefficient is 0.255 $(>0.05) ; 3)$ for the 'analysis' reflexive form is statistically significant $(p<0.01)$.

Thus, during psychoanalysis the reflexive process changes qualitatively and quantitatively, which is reflected in the subject's narrations of his dreams.

\section{Research No. 3. Dynamics of reflexive activity}

of the personality during psychoanalysis (the case of Mrs. M.)

Research of 'reflexive I' and 'regressive I' dynamics.

In all narrations of the dreams words and phrases that are related to the following two categories: 'reflexive I' and 'regressive I' were identified.

Elements related to the 'reflexive I' are the words and expressions showing that the subject is reflexively and observingly active.

Elements related to the 'regressive I' are the words and expressions related to the past of the subject.

For each dream, character frequency coefficient was calculated for the 'regressive' and 'reflexive' elements. According to the data obtained, a diagram for each category was drawn. For each of the three periods of psychoanalysis average character frequency for the two categories was calculated separately. The results were processed with the statistic package SPSS.

Results:

1. According to the 'reflexive I' average character frequency diagram, its dynamics is the following: from the first to the second period the 
amount of words in this category decreases; from the second to the third period grows again. Such results show that by the beginning of psychoanalytical process the subject had already formed her own reflexive ability, but it was used counterproductively and did not induce the solution of inner conflicts, and could even aggravate them. During psychoanalysis the patient started reconsidering own thinking abilities, which made her reject the former reflection schemes and gradually identify with the new analytical reflexive ability of thinking about herself and developing her 'reflexive I' (Rossokhin \& Izmagurova, 2004).

Statistic data processing showed that the difference between the three periods' indexes is statistically significant $(p<0.01)$.

2. Dynamics of the 'regressive I'-related elements is the following: from the first to the second period the amount of words in this category increases; from the second to the third period it reduces. It can be explained by the fact that during psychoanalysis the subject regresses to deeper psychic states (Aron \& Bushra, 1988). Together with the simultaneous strengthening of the 'reflexive I' it can mean that the subject's reflexive ability grows even during strong regression (Rossokhin \& Izmagurova, 2004). The subject doesn't lose the reflection ability while deepening own regressive altered states of consciousness, but even strengthens it, which helps the patient to understand his / her own inner world and his/her own personality much better.

Statistic data processing showed that the difference between the three periods' indexes is statistically significant $(p<0.01)$.

\section{Research No. 4. Intrapsychic dynamics}

of dreams (the case of Mrs. M.)

Analysis of dreams quantity and volume dynamics.

All dreams were extracted from the transcripts of psychoanalytical sessions. The transcripts of the present research contain 200 dreams. The dreams were divided by three equal time periods. The results showed that:

1. During psychoanalysis the volume of narrations of dreams expressed in words increases. In the first period this volume was of 2480 words, in the second one, 8377 words, and in the third it made up 12327 words. It demonstrates that the interaction between the conscious and unconscious psychic content of the patient deepens, there are less re- 
pressed elements and more psychic contents available to memory, emotions and reflexive considering.

2. During psychoanalysis the amount of dreams increases abruptly. Thus, if we divide all the dreams into two equal time periods, we will get 67 dreams in the first period and 133 in the second one, i.e. the quantity of dreams grew by 2 times.

Dynamics of emotional nuances during psychoanalysis.

All emotionally nuanced expressions were identified in the narrations of dreams. For each dream, emotionally nuanced words character frequency coefficient was calculated. For each of the three periods of psychoanalysis the average character frequency coefficient was calculated separately. The diagram was drawn. The results were processed with the statistic package SPSS.

Results. The analysis of emotionally nuanced words dynamics showed that their amount reduces from the first to the second period and increases from the second to the third periods. It shows that during psychoanalysis the subject both learns to analyze her own emotions reflexively and to reconsider and change them. The emotions become more harmonious, integrated, deep, there are no more extreme emotional states. The subject gets the ability to think about her emotional states reflexively. Statistic data processing showed that the difference between the three periods' indexes is statistically significant $(\mathrm{p}<0.01)$.

Analysis of living objects character frequency in the dreams.

All living objects were identified in the narrations about dreams, except the subject herself (for example, "man," "mom," "people" etc.). For each dream their character frequency was calculated. The results were processed with the statistic package SPSS.

Then in the texts of dreams containing living objects all detailed descriptions of living objects were identified, i.e. the objects the subject already knows or the ones she describes in detail ("husband," "masseuse... she is a short, dark-haired woman with sleek hair" etc.). For each dream their character frequency was calculated. The results were processed with the statistic package SPSS.

Results. 1) In general, the quantity of living objects in the narrations about the subject's dreams increases from the first to the third period. Statistic data processing showed that the difference between the three periods' indexes is not statistically significant $(p>0.05)$, but it tends to increase. 
2) The quantity of detailed descriptions of living objects in the narrations about the subject's dreams increases from the first to the third period. Statistic data processing showed that the difference between the three periods' indexes is statistically significant $(p<0.01)$.

Thus, the results show that the interior world of the patient during psychoanalysis becomes gradually more full; the field of inner objects they pay attention to broadens semantically, becomes more detailed and living. New images appear in the inner world of the subject, and he establishes new inner relations with them. At the same time, inner relationships with the objects that already existed before broaden and deepen, and those objects themselves become emotionally richer.

\section{Analysis of 'past' and 'present' categories}

in narrations about dreams.

In all dreams transcripts 3 categories were identified: 1) dreams in a present tense; 2) dreams in a past tense; 3 ) dreams in both kinds of tenses.

Then we only worked with categories 1 and 2 .

Average character frequency coefficient for the two categories was calculated separately for each of the three time periods. According to the data obtained, a diagram was drawn for each category.

Results. The research showed that the amount of present-tense narrations reduces from the first to the third period, and the past-tense narrations increase. It demonstrates that with time, the patient starts reconsidering their dreams reflexively before telling them to the psychoanalyst. Thus, at the beginning of psychoanalysis the subject tells the dreams 'untouched, aims the narration at the analyst only, lives them through 'here and now. Then during psychoanalysis the subject acquires the ability to reconsider their dreams reflexively even before meeting the analyst. Coming to the session, the subject talks about their dreams in past tenses because he has done some reflexive work with them.

\section{Research No. 5. Dynamics of qualitative content of reflexive processes}

In this qualitative empirical research, we would like to obtain a more exact answer to the questions if reflexive processes of a personality really change during psychoanalysis and what the specifics of this changes are. To do that, we will not only examine the dynamic of reflection-re- 
lated words using their character frequency, but also take into account the words that are indirectly associated with reflection but according to the experts are related to reflection evaluation. Those are such words as "look," "see," "watch," "look for," "find" etc., which are associated with any kind of reflective-analytical work done by the patient. Thus we pass on to a deeper level of reflexive processes analysis.

The words "look" and "see" (the case of Mrs. W.)

One of the most frequent words in Mrs. W.'s I-context was the word "look," which is indirectly associated with reflexive processes. The following research was conducted. All her narrations about dreams during two years were divided into two groups (the first and the second year of psychoanalysis). From each of them every verb "look" was extracted and written down with the number of the dream. This helped to find out that in the second year dreams a new perception verb - the verb "to see" appears, and the word "to look" appears less often.

Such a result might be an example of increase of reflexive activity of the personality. If at the first stages Mrs. W. only looks (passively), as time passes, she becomes capable of seeing (actively), i.e. realizes what she is seeing and how she perceives it.

The words "look" and "see" (the case of Mr.X.)

We have conducted a qualitative and quantitative analysis of perception related verbs character frequency: "look carefully" (peek, glance), "look," "not see," "see" and "watch." The abovementioned words were extracted from each narration about a dream and were written down with the dream number. As a result, the average character frequency of each verb according to the three psychoanalysis years was calculated.

Results are statistically significant $(\mathrm{p}<0.01)$. In the first psychoanalysis year the patient usually "looks carefully," "peeks" but "does not see anything." By the second year, he starts to "see" and "watch," less "looks carefully" and more just "looks." In the third year, the subject does not "look carefully" at all, and much more "sees" and "watches." Such data can testify that during psychoanalysis the subject acquires the capability of reflexive watching his personality and can "see" many conflict aspects of his inner world that were unavailable to him before.

The words "seek" and "find" (the case of Mr.X.)

One of the most significant and frequently used words for Mr. X's narrations about his dreams is the verb "to seek." We consider this verb 
to be related to the reflective work of a personality. The verb "to find" is also of special importance in this context because it can be considered as a result of the activity related to the former verb "to seek." We have analyzed different forms of using those verbs in various periods of psychoanalytic process (the research method is similar to the former case).

Results. In the first year, the patient "seeks" but "does not find" most frequently. In the second year, the quantity of words "haven't found" decreased, while that of the word "found" increased. In the third year, the subject "seeks" much less, "finds" more often, and speaks more often about "seeking" in the past. All of this can be considered as an indirect evidence of the activation and transformation of the subject's reflexive activities during psychoanalysis.

The verbs "feel" and synonyms (the case of Mr.X.)

In this case, we have calculated and analyzed the character frequency dynamics for different forms of perception- and feeling-related words during psychoanalysis.

Results. The character frequency of feeling-and perception-related words using increased notably, i.e. the subject started talking more about his feelings and emotions. The increase of capability to talk about one's inner feelings can demonstrate the deepening of the subject's reflexive processes and their orientation at "more fine" and unavailable before emotional layers of one's inner world.

Dynamics of the 'I'-image in narrations about dreams

(the case of Mr.X.).

One of the key aspects of 'I-presentation' of Mr. X. is his description of himself as "I-child" and "I-adult." Often these two descriptions appear in his discourse simultaneously, when the subject talks of 'ambiguity": "I feel as if I were a double person," "I'm a kid and at the same time I'm an adult," or "we are playing in childhood, but I am a grown-up."

Basing on that, we have calculated the average character frequency of three categories of dreams: 1) dreams where the subject feels as a boy and acts like a small boy in his childhood, 2) dreams where the subject feels as an adult and acts like an adult, 3) dreams where the subject feels ambiguous age. The figure was obtained by dividing the quantity of dreams in a certain category in a year of psychoanalysis by the total amount of dreams in the same year. 
Results. In the first year of psychoanalysis, the subject feels and acts like a little boy more often, and his descriptions are ambiguous ("my body is child-like, I'm a boy, but act as an adult"). The second year is characterized by abrupt decrease of ambiguity, the subject starts "growing up" gradually. In the third year the subject becomes more and more 'adult' and less often feels as a kid. Such a result can also be an indirect evidence of growing reflection capability: the subject acquires the ability to distinguish his states and to describe them verbally, and passes on to a 'more adult' level of perception and description of his own inner reality.

\section{Research No. 6. Dynamics of sense content of important inner reality objects during psychoanalysis}

To conduct this research, we have developed a methodic of deciphering of movement of unconscious associations of the patient during psychoanalytical process.

It includes the following stages:

1. The most important object(s) is / are identified in the patient's narrations about their dreams.

2. The context of the object is identified (three words before and three words after the object).

3. The most frequent context word is identified.

4. The context of this word is identified similarly.

5. This procedure repeats several times. Then important connections are identified (if there are any) and are analyzed qualitatively.

Results (the case of Mrs. W.).

1. The important object for Mrs. W. is her female friend Sasha.

2. The context of the word "Sasha" is identified (three words before and three words after the word "Sasha").

3. The most frequent word in the context for "Sasha" is the verb "to sit" (i.e. in the patient's dreams, Sasha usually is seated).

4. The context for the verb "to sit" is identified in the patient's narrations of her dreams.

Having identified the context for "to sit," we find out that before appearing in the series of Mrs. W.s Sasha-dreams, it had been present in a series of dreams related to Mrs. W. herself and is expressed as "I'm sitting." Such a result is a good confirmation of the hypothesis of the psy- 
choanalytic about Mrs. W.s friend Sasha: Sasha is an image presenting the rejected part of Mrs. W.s own personality.

This hypothesis can also be confirmed by the content of dreams featuring Sasha:

- “...I beat poor Sasha again." "....in the dream I started beating her again.” “...she irritates me...” “...I'm mad at her." “...I just beat her.”

- "Sasha is sitting and eating..." "it makes me mad at her..." “...I shout at her, yell something." "she made me mad in the dream."

In the following dreams (close to the end of the second psychoanalysis year) the contexts of the word "to sit" often contained the form "I was sitting" or "I sat" (past tenses). It can be evidence of the fact that during psychoanalysis Mrs. W. managed to work with the theme of "Sasha" and form a more positive attitude to this part of her personality.

Research dynamics of Oedipus conflict (the case of Mr.X.).

Here we present the results of the empirical research of expression of Oedipus complex in Mr. X.'s narrations about his dreams. The change of the images of the parents and ' $\mathrm{I}$ ' of the patient during psychoanalysis was researched, as well as the dynamics of interaction of those inner images.

Research of father's image in the narration of dreams.

1) Character frequency of father's image in the dreams.

For each of the three psychoanalysis years, the average character frequency of father's image in the dreams was calculated (the quantity of dreams with the image of father in a certain year of psychoanalysis divided by the total amount of the dreams in the year). According to the results, a diagram of the character frequency of father's image was drawn, showing that this figure increased significantly $(p<0.01)$, i.e. father's image appeared in the dreams more often.

2) Results according to the methodic of deciphering of movement of unconscious associations.

1. Building the context for the words "father" and "Dad," describing the image of the patient's father.

2. The most frequent word is "home."

3. Building the context for the word "home."

4. The most frequent word is "my."

5. Building the context for the word "my."

6. The most frequent word is "friend." the word "my dear" is also frequently used. Thus we can suppose that as time passed, the subject grew to consider his father as a very close friend. 
3) Dynamics of father's image.

Analyzing the context dynamics for the words "father" and "Dad" we found out that in the first psychoanalysis year the patient almost always used the word "father," then in the second year started calling him "my father," and in the third year almost always (except for once) he used the word "Dad."

4) Dynamics of the context for "father," "my father" and "Dad."

In this case from the father's image context the most frequent words were identified related to different categories of this image.

The words related to the 'father' figure: "relatives," "cry," "run away from father," "father will cut off the penis" (in all the cases the 'father' is perceived as a threatening object, and just as a relative).

The words related to the "my father' figure: "relatives" (at this stage, 'my father' is regarded still as just one of the relatives); "my father and I," "my father with me" ('my father' is not threatening anymore, he is closer to the patient's I).

The words related to the 'Dad' figure:

- The boy wants to make friend with him, he is as his Dad (the subject starts to want to establish good relations with his father),

- Dad comes out of jail, he is good (now 'Dad' gets rid of his bad characteristics and becomes 'good'),

- "Dad and I are at construction," "we prepare construction materials" (the subject starts 'building' his interior relations with Dad),

- "my wife, my daughter and I like Dad, Mom and I when I was a kid" (talking about his dream, the subject equalizes his today's family and the family of his childhood).

According to the results, the 'father' present at the beginning of the analysis is threatening and scary for the subject. In the second psychoanalysis year, he becomes 'my father', i.e. the patient wants to be closer to him and to make friends with 'Dad.' In the third year, 'Dad' is already 'good,' they can build their relationship together, and the childhood family of the subject equals his normal current situation.

Research of father-replacing figures.

Then, having analyzed all the dream narration texts, we have identified the following important Oedipus-complex-related images.

Threatening male figure - an image of a big strong scary man threatening the patient (the image of the patient in those dreams was "I am little"). 
A 'kind' male - a good and kind man helping the subject.

Father - father's image described by the word "father."

My father - father's image described by the words "my father."

Dad - father's image described by the word "Dad."

For each of the images, average character frequency was calculated for each psychoanalysis year.

Results. The following results were obtained for sense content of father's image. First year: father is replaced by a threatening male figure, while the subject feels as a little boy. Second year: the threatening figure is gradually replaced by the real father ('my father'), the subject almost doesn't feel little. Third year: the subject is not 'little' anymore, there are more 'kind men,' and father becomes 'Dad.'

Research of dreams about threatening situations.

In this research we identified the dreams where there is a threat for the subject and the dreams where such a situation has a positive ending for him. Then average character frequency of both categories was calculated for the three psychoanalysis years. A diagram of the results was drawn, and it showed that as time passes, there are less threatening situations, and the positive endings happen more often. Within the framework of Oedipus conflict research, such a result can be evidence of the fact that during psychoanalysis the patient stops being afraid of the inner image of his father, and there are less and less the dreams with the threatening father-replacing figures.

Research of Oedipus-complex-related image of the subject's 'I'

Having analyzed the average character frequency of the images 'Ichild,' 'I-adult' and 'ambiguity,' all of this, within the Oedipus complex context, can be regarded as its solution and the patient's acquiring more mature and integrated image of himself.

Research of mother's image in the narration about dreams.

Mother's image in Mr. X's dreams is often related to her absence, unavailability, impossibility to be with her. Basing on that, the following research was done. Negative phrases were identified when the subject talked about his mother. E.g. "there is no image of Mom near me," "mom is not at home," "mom is in my apartment...and I am not there in this process." For each psychoanalysis year the average negations quantity was calculated: 1) the quantity of negations in a certain dream was divided by the total amount of words in the dream, 2) for the first, sec- 
ond and third year the average figure was calculated for all the dreams in that year. A diagram was drawn and as a result we saw that during psychoanalysis the mother image-related negations quantity reduces $(p<0.01)$. It can testify that in the course of psychoanalysis the amount of inner conflict situations of the patient related to the psychic 'unavailability' of his mother reduces, and her inner image becomes more available and close.

Research of mother-replacing figure.

Another important aspect in the mother-figure dreams is its convergence with the image of the patient's wife. There is a series of dreams where the mother is the wife (or vice versa), there is an ambiguous characteristic of the female image. E.g. "and my mother - wife is not at home," "the woman is like my mom, but her face and body are my wife's, but I react as if she were my mom."

For the three psychoanalysis years, the average character frequency of the images of the patient's mother and wife was calculated. A diagram was drawn and we can come to the following conclusions basing on the results. First year: the images of the mother and wife are quite sewn together. Second year: the mother appears in the patient's dreams much more often, and the wife - less often, which can be an indirect evidence of the subject's regression during psychoanalysis. Third year: the wife appears much more often in his dreams, i.e. the wife's image goes out of the mother's image and becomes independent in the subject's inner reality. Correlation of this result with the one above shows that when the subject's 'I' was 'little, childish', the wife's image was replaced by the mother's image, and when the subject's 'I' 'grew up', he was able to see the real image of his wife.

Research of the parents' images together

in the dreams of the patient.

In this case, from the subject's narrations about his dreams, the dreams were extracted where mother's image is apart from the father's, as well as the ones where they appear together. Then for the three years average character frequency of father, mother and their images together was calculated.

As a result we can see that as time of psychoanalysis passes father and mother figures appear together more often, and less often they appear apart from each other. This can be evidence of Oedipus complex 
solution: a normal family situation is reflected in patient's inner world father and mother together - is more admissible for the subject and appears in his dreams more often.

\section{General conclusions}

1. During psychoanalytical process, reflexive processes activate, deepen and change qualitatively, which is expressed in particular in the increase of general volume of reflexive statements. The research of intrapsychic dreams dynamics during psychoanalysis showed that extracommunicative orientation of the dreams is replaced by the intrapsychical one, and the content of reflexive processes changes qualitatively. There are less ascertaining statements, more frequent is detailed description of inner emotions and feeling of the subject.

2. As reflection develops, the subject begins considering their dreams reflexively, which has the following consequences: a) formation of the active 'reflexive I'; b) increase of dreams quantity and volume; c) harmonization of emotional expression and increase of the subject's ability to describe their emotions verbally; d) filling and structurization of the inner world; e) quantitative change of intrapsychic images: there are more relations between the images, and the image space increases; e) qualitative change of inner images: they are brighter, more concrete, more multilateral; f) relations between different images change; g) reflexive processes start concentrating around certain images.

\section{References}

Asmolov, A.G. (1996). Kul'turno-istoričeskaâ psihologiâ i konstruirovanie mirov. [Cultiral-Historical Psychology and Constructing of the Worlds]. Moscow: Smysl.

Aron, L.A., \& Bushra, A. (1988). Mutual Regression: Altered State in the Psychoanalytic Situation. Journal of the American Psychoanalytic Association, 46, 389-412.

Colombo, D., \& Michels, R. (2007). Can (Should) Case Reports Be Written for Research Use? Psychoanalytic Inquiry, 27, 640-649.

Dahl, H. (1972). A Quantitative Study of a Psychoanalysis. Psychoanalysis and Contemporary Science, 1, 237-257.

Dahl, H. (1974). The Measurement of Meaning in Psychoanalysis by Computer Analysis of Verbal Contexts. Journal of the American Psychoanalytic Association, 22, 37-57. 
Ellman, S. (2005). Psychoanalysis and Research. Journal of the American Psychoanalytic Association, 53, 639-643.

Fonagy, P. (Ed.). (1999/2002). An Open Door Review of Outcome Studies in Psychoanalysis. London: International Psychoanalytical Association.

Freud, A. (1973). The Ego and Mechanisms of Defense. New York: International University Press.

Gullestad, S.E. (2007). Psychoanalysis and Empirical Research. Scandinavian Psychoanalytic Review, 30, 113-117.

Kernberg, O.F. (2006). The Pressing Need to Increase Research in and on Psychoanalysis. International Journal of Psycho-Analysis, 87, 919-926.

Lewin, B.D. (1955). Dream Psychology and the Analytic Situation. Psychoanalytical Quarterly, 24, 169-199.

Luborsky, L., Barber, J., \& Diguer, J. (1993). The Meanings of the Narratives Told During Psychotherapy: The Fruits of a New Operational Unit. Psychotherapy Research, 2, 277-290.

Rossokhin, A.V., \& Izmagurova, V.L. (2004). Ličnost' v izmenennyh sostoâniâh soznaniâ $v$ psihoanalize i psihoterapii [Personality in the Altered States of Consciousness]. Moscow: Smysl.

Rossokhin, A.V. (2009). Refleksiâ nerefleksivnogo ili upravlenie ISS [Reflection of Non-Reflexive Psychic Content or Management of the Altered States of Consciousness]. Bulletin of University (The State University of Management), 1, 87-92.

Tolchin, M., \& Carr, R.B. (2007). Proceedings of the Fourteenth Annual Conference of the Consortium for Psychoanalytic Research: Dreams in Psychotherapy: An Integrative Approach. Journal of the American Academy of Psychoanalysis, 35, 669-676.

Wallerstein, R.S. (2009). What Kind of Research in Psychoanalytic Science? International Journal of Psycho-Analysis, 90, 109-133.

Wyatt, F. (1986). The Narrative in Psychoanalysis: Psychoanalytic Notes on Storytelling, Listening and Interpreting. In F. Wyatt (Ed.), Narrative Psychology: The Storied Nature of Human Conduct (pp. 193-210). New York: International University Press. 